\title{
The Impact of ICT Acquisition, Online courses, and Management System on Cultural Differences and English Language as Related to the Moderator Effort Expectancy: A Case Study at EPU
}

\section{Bnar Abdulmajeed Ghafour}

Department of International Marketing and Languages, College of Erbil Technical Administration, Erbil Polytechnic University, Erbil, Kurdistan Region, Iraq.

bnar.ghafour@epu.edu.iq

\section{Shirzad Mohammed Mahdi}

Department of International Marketing and Languages, College of Erbil Technical Administration, Erbil Polytechnic University, Erbil, Kurdistan Region, Iraq.

shirzad.mahdi@epu.edu.iq

\section{ARTICLE INFO}

\section{Article History:}

Received: $11 / 11 / 2021$

Accepted: $13 / 12 / 2021$

Published: Autumn 2021

\section{Keywords:}

Information

and

Communication

Technology

Cultural Differences,

Learning Management

System (LMS), English

Language, E-learning,

Online courses.

Doi:

10.25212/lfu.qzj.6.4.32

\section{ABSTRACT}

This study was conducted to discover the connection between the use of ICTs and English language achievement of students at EPU. The objectives of the study are to study the relationship between the use of ICTs and English language achievement of freshmen level students. The population of the study included all the students which are enrolled in first stage of all department colleges at ERBIL Polytechnic university in Iraq-Kurdistan. The sample of the study comprised 209 students including 111 females and 98 males. The data was collected by a self-developed questionnaire which was based on the students' opinions related to the use of ICT. All the 209 students answered the questions of four-point Likert type questionnaire that had 15 items. Data were collected from first stages students (both male and female) of three colleges that include numerous departments. The data gathered from the students were analyzed on IBM SPSS Amos and SPSS. Standard deviation was calculated to find the major results. The study found the benefits and major roles of ICT in education sector specifically in learning English language in class and online classes during the pandemic COVID19. Also explored that ICT 
helps student to obtain management system; students' performance, quality, capability and value.

\section{Introduction}

The increasing need of students, employees, and business managers, to interact across linguistic boundaries. In the developing world, the education philosophy of the Universities can only be rational for all aspects of everyday life, if there is much focus on their Management System such as (Quality, Performance, Capability, and Value) and also communication barriers by researchers and practitioners engaged in international business and management. In teaching and learning process, EPU has adopted the blended approach to classroom instruction. Blended approach refers to "learning models that combine traditional classroom practice with e-learning solutions." For example, "students in a traditional class can be assigned both printbased and online materials, have online mentoring sessions with their lecturer through chat, and are subscribed to a class email list. Also, a web-based training course can be enhanced by periodic face-to-face instruction." This is to ensure that the benefits of both the traditional method and the ICT independent model are availed to students in their learning. ICT is not intended to substitute lecturers, but to be used as an enrichment to teaching/learning process. Therefore, the face-to-face approach of classroom instruction should not be dispensed because of technology. Research on the use of ICT to enhance teaching and learning, though some scholars claim that these studies are inconclusive, nonetheless, they point to the fact that ICT in education can make both positive and negative impact on students' learning. It is, therefore, necessary to review both the positive and the negative impacts of ICT in learning for a holistic view and to have a balanced understanding of the phenomenon under study. On the positive side, of Quality, Performance, Capability, and Value, affirm that technology is revolutionizing teaching and learning in various ways and suggest the need for teachers and students to exploit technology in order to modify pedagogy. It's Founded that technology, cultural differences, and English language generated students' interest during the courses, improve learning and understanding of the materials, provide useful feedback on assignments and improve interaction between learners and lecturers to achieve quality, performance, capability, and value. 


\section{QALAAI ZANISTSCIENTIFIC JOURNAL \\ A Scientific Quarterly Refereed Journal Issued by Lebanese French University - Erbil, Kurdistan, Iraq \\ Vol. (6), No (4), Autumn 2021 \\ ISSN 2518-6566 (Online) - ISSN 2518-6558 (Print)}

However, despite the positive impact reported in these studies, the use of technology in teaching and learning has its problems and challenges. For instance, technology has been said to encourage student laziness since it makes it easy for them to take short cuts and not put effort into their writing; they may 'copy and paste' and download material from the internet without acknowledging sources. At the click of the mouse, technology provides students with a whole range of information; consequently, creativity, critical thinking and problem-solving abilities are stifled. Indeed, the EPU has provided ICT facilities and infrastructure for teaching and learning which are comparable to any modern learning environment in Kurdistan and the world. On the other hand, the outbreak that was declared a Public Health Emergency of International Concern on 30 January 2020 because of the COVID-19 pandemic, is the first and foremost health crisis that affected the educational sector to a great extent. Lecturers and students are all departed. Teaching moved to online, they are predicted to access electronic platforms, on line applications and classes to keep the educational process at home on an untested and unprecedented scale. In the light of the above, this study investigates how these resources are utilized by first year students especially in their learning of academic English subject.

\subsection{The research purposes}

The purpose of this research is to evaluate the impact of information and communication technology (ICT), on learning English Language, learning management system (LMS); and how cultural differences affects students' learning in both aspects during the first course. As well as the study aims at finding out the impact of shifting the learning process form classes into home, and find out the extent of handling electronic learning from the part of the students and the number of benefits that they could take from it. The study aims at revealing the positive use of technology in teaching and learning English subject on organizational and students' learning Quality, Performance, Capability and Value at EPU.

\subsection{The Research Problems}

As higher education's imposing unplanned experiment with remote learning this year approaches its end, its necessary to evaluate how ICT role in learning process of 


\section{QALAAI ZANISTSCIENTIFIC JOURNAL \\ A Scientific Quarterly Refereed Journal Issued by Lebanese French University - Erbil, Kurdistan, Iraq \\ Vol. (6), No (4), Autumn 2021 \\ ISSN 2518-6566 (Online) - ISSN 2518-6558 (Print)}

English language went for students, and what is the outcome of student-centered and E- learning? In-depth survey of students for both first and second courses that went virtual offers certain insights into how colleges can recover the deficiencies.

Many first-year undergraduates at EPU seem challenged and overwhelmed with integrating ICT and English Language into their learning. The use of ICT and the English Language and management system in learning presents a huge challenge. These students are familiar to the traditional teaching approaches where the teacher dictates or writes notes on the board and distributes handouts; but at college, PowerPoint presentation and sound system are used in most of the classes. Students were required to prepare different assignments, essay, report, and project by taking benefit from national websites, without being trained and prepared to cope with the new system, as they haven't been experienced these skills and assignments at high school, thus it causes a big gap in organizational and students' learning Quality, Performance, Capability and Value. In addition, in the beginning of the second course, as a result of the COVID-19 pandemic, which is the first and most health crisis, all the educational organizations decided to shift learning process into E-leaning and online classes on an untested and unprecedented scale. The teaching staff and students are contacting through Moodle, Edmodo and zoom with a lot of trial and error and uncertainty for everyone. As materials are posted on these platforms and students are required to browse their classes constantly, research online for assignments and projects, and do online quizzes. Notably, these unexpected shifts will not just be a short-term issue, but probably could also have long-term consequences for the affected partners and possibly increase inequality of their performance, Quality, Capability, and Value negatively.

1.3 Research important: This is to investigate the impact of ICT on students' learning management system focusing on both courses with their different features. ICT can play an important role in managing cultural differences, and learning English Language, as students used technology to fulfill their various ample assignments in both courses. As well as it investigates students' management capacity and techniques in using necessary apps and programs in learning English language during 


\section{QALAAI ZANISTSCIENTIFIC JOURNAL \\ A Scientific Quarterly Refereed Journal Issued by Lebanese French University - Erbil, Kurdistan, Iraq \\ Vol. (6), No (4), Autumn 2021 \\ ISSN 2518-6566 (Online) - ISSN 2518-6558 (Print)}

the pandemic crises, and to what extent they could get benefit from technology for achieving learning Quality, high Performance, Capability and Value.

\subsection{The following objectives are noted in this research:}

1. To identify the relationship among ICT, Cultural Differences and Management System such as (Quality, Performance, Capability, and Value).

2. To enhance the relationship between ICT and learning English Language regarding the Quality, Performance, Capability, Value needs.

3. To identify the relationship among Effort expectancy and ICT, Cultural Differences, English Language and Management System such as (Quality, Performance, Capability, Value).

4. To investigate students' capability in managing ICT in learning English during the pandemic crises.

5. To find out the level of student's achievement regarding managerial system such as (Quality, Performance, Capability, Value) in both courses.

1.5 The researcher will evaluate the questions below to obtain the objectives listed above:

1: What is the mechanism between ICT and Cultural Differences, Management System such as (Quality, Performance, Capability, and Value)?

2: What is the relationship between English Language and learning Management System such as (Quality, Performance, Capability, and Value)?

3. How can Effort expectancy and ICT, Cultural Differences, English Language and Management System (Quality, Performance, Capability, and Value) correlate?

4: How students are capable of managing ICT in learning English during the pandemic crises?

5: What is the level of student's achievement regarding managerial system such as (Quality, Performance, Capability, and Value) in both courses? 


\section{QALAAI ZANISTSCIENTIFIC JOURNAL \\ A Scientific Quarterly Refereed Journal Issued by Lebanese French University - Erbil, Kurdistan, Iraq \\ Vol. (6), No (4), Autumn 2021 \\ ISSN 2518-6566 (Online) - ISSN 2518-6558 (Print)}

\subsection{Research Model}

\section{Explanation of Figure 1}

The model of ICT contemporizes the student's study. It represents its possessions and the actual relationship with the students. From this perspective, ICT can play a significant role in regulatory focus on cultural differences, English Language, and management system. Most educators have found a fundamentally positive relationship between ICT and cultural differences, and English Language, irrespective of the sector of the productivity measure used, the unit of analysis, and the ICT observes incorporated. Exactly how ICT distresses the teaching importance, learning explanation of students' quality, performance, capability, and value. This system improves university's effectiveness and studies regulatory focus on the relationship between cultural differences and English Language is the mediator of the ICT, and management system. ICT moderating of effort expectancy in teaching and learning perform a significant role in student's quality, performance, capability, and value. The right students with the right skills in the system, encourage proactive moderating of effort expectancy in achieving tasks which lead to a regulatory focus in the EPU there for it contributes to more management System such; quality, performance, capability, and value.

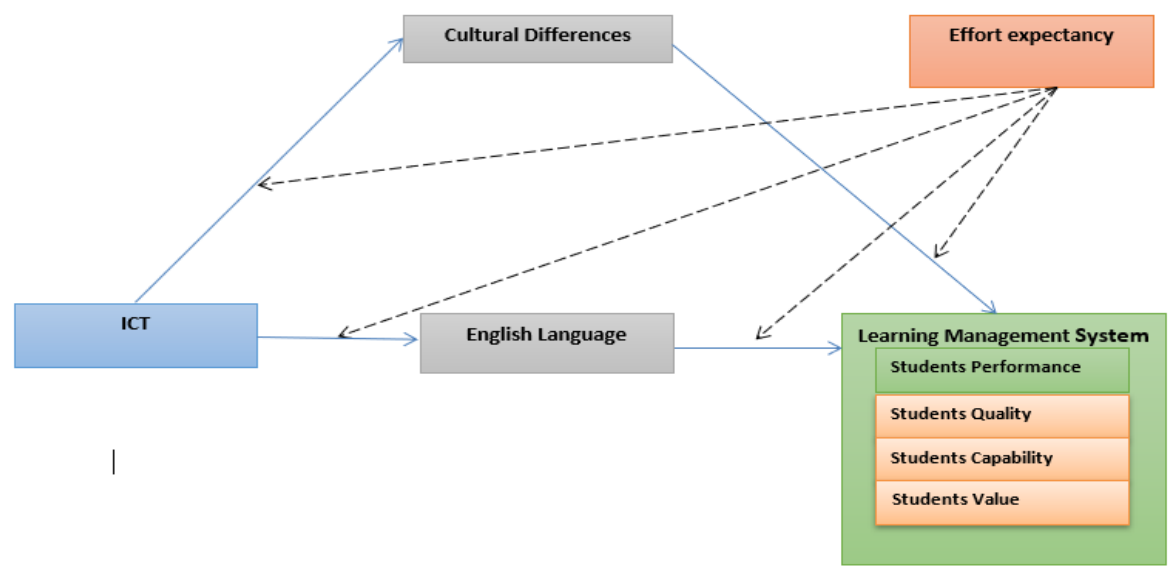

Figure 1: Research Model (1)

Classical Researches display the implementation of ICT. Universities can bring superior influence on students, Regulatory focus: differences in Cultural, English 


\section{QALAAI ZANISTSCIENTIFIC JOURNAL \\ A Scientific Quarterly Refereed Journal Issued by Lebanese French University - Erbil, Kurdistan, Iraq \\ Vol. (6), No (4), Autumn 2021 \\ ISSN 2518-6566 (Online) - ISSN 2518-6558 (Print)}

Language and Management System, in the classroom. The corresponding HR practices can be strictly used in organizations to adopt a model of ICT. Specific studies indicate the relationship between ICT, students and organizational outcomes such as managerial performance; it can expect that student's attitudes and university lecturer can affect the relationship between ICT, culture, English Language, and management System. The present study highlights students and university lecturer activities plays both intervening and moderating roles in the connection between superficial HR practices and student outcomes, such as Management System such as (Quality, Performance, Capability, and Value). The research model shows conceptualized ICT, culture, and the English Language affected in a way to support the overall corporate goals set by the universities. Fundamentally, students and university lecturer's work together to create quality, performance, capability, and value, select, develop, and retain individuals in the context of introducing acceptable HR practices. ICT help in increasing the number of trained students, particularly at universities. It embraces up staff, also better-trained and more difficult classrooms will be more able to exertion separately and flexibly. The ado models in the association discusses the situations in which top management will consistently apply human resource practices to achieve immeasurable management system to the class as well as quality, performance, capability, and value. That outcome can support university students to become a source of substantial competitive advantage. Specifically, their study indicates that when appropriately utilized, technology increased learners' motivation, engagement, and participation by providing novelty and variety, creating interest and excitement and adding more fun to the classroom.

\section{Explanation of Figure 2}

This model provides a strong side to the versatility of independent Online Courses and the development of infrastructure, viewed by the dependent Learning management systems, and mediators in the English language. It thus adds additional ability, value, efficiency, compartmental versatility, and innovation to students. Perceived effort expectancy from a positive. Learning management systems such as Quality, Performance, Capability, and Value. 


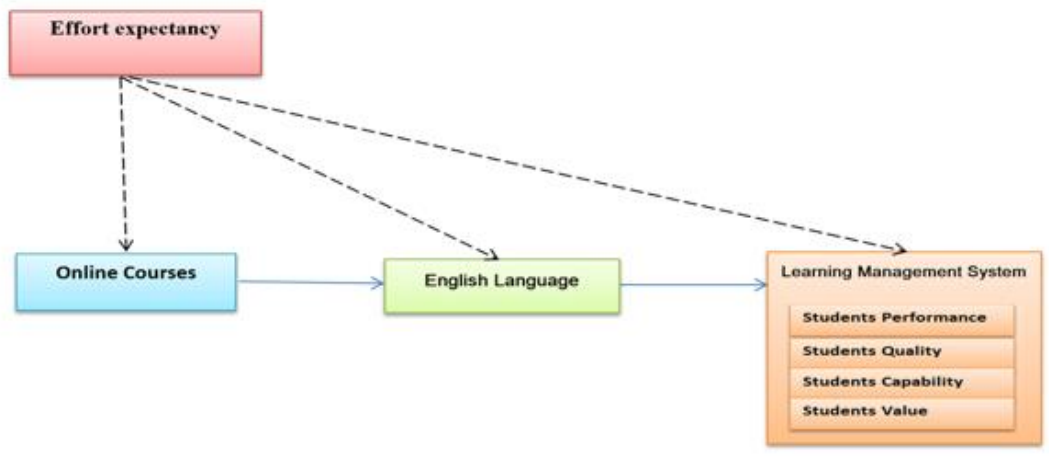

Figure 2: Research Model (2)

In addition, the study included a positive partnership with Online Courses and the development of infrastructure and Effort expectancy moderator. It also led to more promotion of English language, capabilities, importance, qualities with moderator Effort expectancy in the Online Courses.

\subsection{Hypotheses:}

Based on core study about the effect of ICT and Online Courses and development of infrastructure, The hypotheses have been formulated to investigate and study the current research's main issues:

\section{Model 1:}

Hypothesis 1: ICT is significantly related to Mediates of Cultural Differences, English Language, (H1a), Moderating of Effort expectancy ( $\mathrm{H} 1 \mathrm{~b})$, and also consequently affected to Management System, (Quality, Performance, Capability, and Value) (H1c).

Hypothesis 2: Effort expectancy are positively related to ICT (H2a), Management System, (Quality, Performance, Capability, Value) (H2b). And also, positively relate to Mediates of Cultural Differences, English Language ( $\mathrm{H} 2 \mathrm{c})$.

Hypothesis 3: Cultural Differences, English Language backgrounds affect student's Effort expectancy (H3a), ICT (H3b), utilization in Management System, (Quality, Performance, Capability, and Value) (H3c). 


\section{QALAAI ZANISTSCIENTIFIC JOURNAL \\ A Scientific Quarterly Refereed Journal Issued by Lebanese French University - Erbil, Kurdistan, Iraq \\ Vol. (6), No (4), Autumn 2021 \\ ISSN 2518-6566 (Online) - ISSN 2518-6558 (Print)}

Hypothesis 4: Management System, (Quality, Performance, Capability, and Value), are positively relate to ICT, (H4a), Moderating of Effort expectancy (H4b), and Mediates of Cultural Differences \& English Language $(\mathrm{H} 4 \mathrm{c})$.

\section{Model 2:}

Hypothesis 1: Online courses are positively relate to Moderating of Effort expectancy (H1a) and Mediates of English Language (H1b). And also positively relate to Management System, (Quality, Performance, Capability, and Value) (H1c).

Hypothesis 2: Management System, (Quality, Performance, Capability, and Value), are positively relate to Online courses, (H2a), Moderating of Effort expectancy (H2b), and Mediates of English Language $(\mathrm{H} 2 \mathrm{c})$.

Hypothesis 3: English Language mediates the relationship between online courses (H3a), and Management System, (Quality, Performance, Capability, and Value), (H3b).

Hypothesis 4: Effort expectancy as moderator affirmative related to online courses (H4a), Management System, (Quality, Performance, Capability, and Value), (H4b).

\section{Literature Review}

\subsection{Information and Communication Technology (ICT)}

Information and communications technology (ICT) is an extended term for information technology (IT) which stresses the role of unified communications and the integration of telecommunications (telephone lines and wireless signals), computers as well as necessary software, its storage and the audio-visual systems, which enable all users to access, store, transmit, and manipulate information. Murray, James (2011). The term ICT is also used to refer to the combining of audiovisual and telephone networks with computer networks through a single cabling or link system. There are large economic incentives (huge cost savings due to elimination of the telephone network) to merge the telephone network with the computer network system using a single unified system of cabling, signal distribution and management. At EPU, all first-year undergraduates take an ICT course which exposes them to the use of computers in learning and to the LMS platforms-Moodle and Blackboard. In addition, the IT department organizes training sessions through 


\section{QALAAI ZANISTSCIENTIFIC JOURNAL \\ A Scientific Quarterly Refereed Journal Issued by Lebanese French University - Erbil, Kurdistan, Iraq \\ Vol. (6), No (4), Autumn 2021 \\ ISSN 2518-6566 (Online) - ISSN 2518-6558 (Print)}

orientation workshops and offers regular support to students throughout the academic year, Motshegwe, Molefe Mookana and Batane, Tshepo (2015). It is important to understand the background of the first-year students in this study. Most of the students at EPU have experienced a traditional environment where teaching /learning process are done in the traditional mode. They used print media tools such as books, notes, handouts. Teachers dictated or wrote notes on the chalkboard and students copied it. That is to say, these students are used to the traditional teaching approaches in traditional classrooms. Mathur, Piyush (2017).

\subsection{Cultural Differences}

International business, foreign direct investments, expatriates work and any international cooperation require an understanding of the differences between cultures. For example, business negotiations, expatriate professionals, management of foreign personnel, and cross-cultural teams presuppose a good knowledge of cultural differences. Studies abound with recommendations on how to increase expatriate success in a new culture. Black, Mendenhall and Oddou (1991) introduced three main skill areas that expatriates need to focus on to survive in a new culture: skills related to maintenance of self, skills relating to fostering relationships with host nationals and skills that promote a correct perception of the host environment and its social systems. Berry, Kim and Boski (1988). Introduced three strategies for coping with this adjustment process. Expatriates can adjust psychologically by adjusting their behavior to the environment, or they can adjust by changing the environment, or they can move to a more congenial environment. Hofstede (1984) defines culture as 'the collective programming of the mind that distinguishes the members of one human group from another'.

\subsection{English language}

The worldwide spread of English is just one of the many different developments subsumed under the general phenomenon of globalization. It is furthermore associated with boundless mobility and, as such, is the language of globalizations, Gnutzmann \& Intemann, (2008). If, on the one hand it is true that language is a vital commodity in the globalized world, it is on the other also true that globalization raises 


\section{QALAAI ZANISTSCIENTIFIC JOURNAL \\ A Scientific Quarterly Refereed Journal Issued by Lebanese French University - Erbil, Kurdistan, Iraq \\ Vol. (6), No (4), Autumn 2021 \\ ISSN 2518-6566 (Online) - ISSN 2518-6558 (Print)}

issues for second language learning and teaching. As a result, the function of English as an international tool or as a lingua franca (ELF) for communication needs rethinking in the English as a foreign language classroom. This does not only require that teachers help their students develop the linguistic skills needed to understand various kinds of accents and in turn be understood by others, but it also paves the way for an enhanced awareness of the existence of non-native speakers all over the world who use English as a means of communication.

\subsection{Management System}

A management system is the way in which an organization manages the inter-related parts of its business in order to achieve its objectives, Mick Will (2019). These objectives can relate to a number of different topics, including product or service quality, operational efficiency, environmental performance, health and safety in the workplace and many more. The level of complexity of the system will depend on each organization's specific context. For some organizations, especially smaller ones, it may simply mean having strong leadership from the business owner, providing a clear definition of what is expected from each individual employee and how they contribute to the organization's overall objectives. Popular Mechanics, (2000). Similarly, Students' activities in a virtual environment can be aided by teaching and learning management technologies included in various e-learning systems such as Learning Management Systems (LMS) or Learning Content Management Systems (LCMS) (LCMS).

\subsection{Online learning}

As learning is the process of acquiring knowledge, skills, experience, etc. it can be Instructor-Led Training or online learning. Electronic platforms and online courses are useful ways of learning during normal and abnormal situations. Students can be provided with all the necessary materials so as to follow their courses and continue the process of learning even in the most challenging situations most likely as usual. Shivangi Dhawan1 (2020). Integrated model is the most similar to a full online course that are frequently delivered with a sophisticated learning management system. They include chances for computer conferencing, small group-based collaborative online 


\section{QALAAI ZANISTSCIENTIFIC JOURNAL \\ A Scientific Quarterly Refereed Journal Issued by Lebanese French University - Erbil, Kurdistan, Iraq \\ Vol. (6), No (4), Autumn 2021 \\ ISSN 2518-6566 (Online) - ISSN 2518-6558 (Print)}

learning activities, and online assessment of learning outcomes, as well as the availability of much of the subject information in electronic format. Sakshi\& Dhull (2017). E-learning can supply education partners with sufficient merits. It can resolve huge numbers of students in traditional classes, the availability of proper class size, class time, and availability of compulsory instructors. (Nguyen, 2015).

\section{Methodology}

In this research, the impact of the ICT on students' learning English language and management system focusing on both courses with their different features is evaluated. It similarly reveals the effect of culture and effort expectancy on students learning before and during the Pandemic Covid 19 period at EPU.

The sample for this study contains first stage students from Erbil Polytechnic University in Erbil-Kurdistan. The frequency of the variables shows that the age of the respondents was from 18 to 46 years. According to statistical analysis, among the 209 participants, there were 98 males and 111 females, accounting for $47 \%$ and $53 \%$ of the total number of participants respectively. In terms of the participant's education level, high school accounted for $87 \%$, and Diploma accounted for $13 \%$. This study has employed the survey method, using the questionnaire as instruments of data collection. It is developed in English; thus, typical translation and back-translation procedures were adopted to convert the language to simple Kurdish by an expert translator. 209 survey form were sent to the participants through an economically and safety efficient (google form, and email) means during the pandemic Covid 19 Period. From the data analysis, it's perceptible that ICT has an essential role in managing students learning in terms of performance, quality, capability, and value. Correspondingly, students are expected to make efforts in fulfilling their electronic and online tasks of English subject classes. 


\section{QALAAI ZANISTSCIENTIFIC JOURNAL}

A Scientific Quarterly Refereed Journal Issued by Lebanese French University - Erbil, Kurdistan, Iraq

Vol. (6), No (4), Autumn 2021

ISSN 2518-6566 (Online) - ISSN 2518-6558 (Print)

\section{Results}

\section{4.1Data Analysis:}

Table No. (1), shows that the percentage of females among the respondents is greater than the percentage of males, as it reached (53\%) and (47\%) respectively, and this indicates that the majority of the respondents were females.

\begin{tabular}{|c|c|c|c|}
\hline \multicolumn{4}{|c|}{ Table (1) Table (1): Demographic Analysis } \\
\hline & & Frequency & Percent \\
\hline \multirow[t]{3}{*}{ Gender } & Male & 98 & 47 \\
\hline & Female & 111 & 53 \\
\hline & Total & 209 & 100 \\
\hline \multirow[t]{4}{*}{ Age } & $18-25$ & 179 & 85.6 \\
\hline & 26-45 & 28 & 13.4 \\
\hline & 46-Over & 2 & 1.0 \\
\hline & Total & 209 & 100.0 \\
\hline \multirow{6}{*}{$\begin{array}{c}\text { Education } \\
\text { level }\end{array}$} & High-school & 181 & 87 \\
\hline & $\begin{array}{l}\text { Associate } \\
\text { degree }\end{array}$ & 28 & 13 \\
\hline & Bachelor & 0 & 0 \\
\hline & Master & 0 & $\mathrm{O}$ \\
\hline & Doctoral & O & o \\
\hline & Total & 209 & 100 \\
\hline
\end{tabular}

Whereas, the ages of individuals of the respondents ranged greater for the category $(18-25)$ and (26-45) by (85.6\%) and (13.4\%) respectively, which indicates that the majority of the respondents are young. As for the educational level, the largest percentage of the respondents belong to holders of high school and diploma degrees, whose percentage was (87\%) and (13\%) respectively, and these two percentages together represent $(90 \%)$ and this is a good indication that the majority of the sample members were freshers, thus It shows the accuracy of the answers, as they haven't experienced blended learning before, and thus it reflects the accuracy of the results.

Table (2): Estimation of reliability

\begin{tabular}{|rrr|}
\hline Var. & Cronbach's Alpha & N of Items \\
\hline ICT use & 0.694 & 4 \\
\hline Online courses & 0.556 & 4 \\
\hline Effort expectancy & 0.784 & 3 \\
\hline English Language & 0.672 & 4 \\
\hline Cultural differences & 0.742 & 3 \\
\hline Management system & $0.70 r$ & 6 \\
\hline Total & .789 & 24 \\
\hline
\end{tabular}

Table No. (2), represents the Estimation of the reliability coefficient, where the reliability of the scale was tested for the questionnaire items for the six variables with 


\section{QALAAI ZANISTSCIENTIFIC JOURNAL \\ A Scientific Quarterly Refereed Journal Issued by Lebanese French University - Erbil, Kurdistan, Iraq \\ Vol. (6), No (4), Autumn 2021 \\ ISSN 2518-6566 (Online) - ISSN 2518-6558 (Print)}

its paragraphs, as well as the reliability coefficient was calculated for the questionnaire items as a whole. The content of the paragraphs was acceptable.

\begin{tabular}{|c|c|c|c|c|c|c|c|}
\hline \multicolumn{8}{|c|}{ Table (3) Correlation Matrix of Model Constructs } \\
\hline & & $\begin{array}{l}\text { ICT } \\
\text { use }\end{array}$ & $\begin{array}{l}\text { Online } \\
\text { courses }\end{array}$ & $\begin{array}{c}\text { Effort } \\
\text { expectancy }\end{array}$ & $\begin{array}{c}\text { English } \\
\text { Language }\end{array}$ & $\begin{array}{c}\text { Cultural } \\
\text { differences }\end{array}$ & $\begin{array}{l}\text { Management } \\
\text { system }\end{array}$ \\
\hline \multirow[t]{2}{*}{ ICT use } & Pearson Corr. & 1 & & & & & \\
\hline & $2 x$ & & & & & & \\
\hline \multirow{2}{*}{$\begin{array}{l}\text { Online } \\
\text { courses }\end{array}$} & Pearson Corr. & $.329^{* *}$ & 1 & & & & \\
\hline & $2 x$ & .000 & & & & & \\
\hline \multirow{2}{*}{$\begin{array}{l}\text { Effort } \\
\text { expectancy }\end{array}$} & Pearson Corr. & $.631^{* *}$ & $.329^{* *}$ & 1 & & & \\
\hline & $2 x$ & .000 & .000 & & & & \\
\hline \multirow{2}{*}{$\begin{array}{l}\text { English } \\
\text { Language }\end{array}$} & Pearson Corr. & $.336^{* *}$ & $.188^{* \prime}$ & $.487^{* *}$ & 1 & & \\
\hline & $2 x$ & .000 & .006 & .000 & & & \\
\hline \multirow{2}{*}{$\begin{array}{l}\text { Cultural } \\
\text { differences }\end{array}$} & Pearson Corr. & $.206^{* *}$ & $.179^{* *}$ & .126 & $.312^{* *}$ & 1 & \\
\hline & $2 x$ & .003 & .009 & .069 & .000 & & \\
\hline \multirow{2}{*}{$\begin{array}{l}\text { Management } \\
\text { system }\end{array}$} & Pearson Corr. & $.269^{* *}$ & $.191^{*}$ & $.252^{* *}$ & $.332^{* *}$ & $.462^{* *}$ & 1 \\
\hline & $2 x$ & .000 & .006 & .000 & .000 & .000 & \\
\hline
\end{tabular}

\subsection{Correlation Analysis}

ICT is significantly related to Mediates of Cultural Differences, English Language, (H1a), Moderating of Effort expectancy (H1b), and also consequently affected to Management System, (Quality, Performance, Capability, and Value) (H1c).

The first hypothesis branches out into: 1 . there is a significant relationship between the independent variable (ICT) and the two mediating variables (Cultural Differences among students, and English language). Through the correlation matrix table No. (), we find that the relationship between the independent variable (ICT) and the two arguments (CUL.D.) and (EL) was significant because the value of (PV) for the value of the correlation coefficient of $(0.03)$ and $(0.000)$ respectively. It was less than the level of statistical significance (0.05), and this means that there is a positive significant relationship between the independent variable and the two arguments and their value is $(0.20)$ and $(0.31)$ respectively, that is, whenever the values of one of the two variables change (the independent and the mediator), the other variable changes in the same direction by (20\%) And (31\%). 


\section{QALAAI ZANISTSCIENTIFIC JOURNAL}

A Scientific Quarterly Refereed Journal Issued by Lebanese French University - Erbil, Kurdistan, Iraq

Vol. (6), No (4), Autumn 2021

ISSN 2518-6566 (Online) - ISSN 2518-6558 (Print)

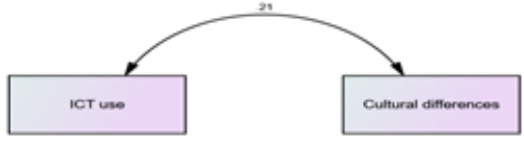

Figure (3): Measurement correlation Model between ICT use and Culture differences

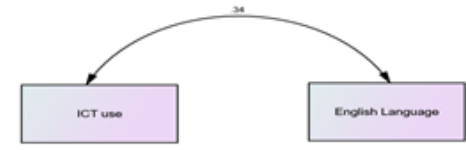

Figure (4): Measurement correlation Model between ICT use and English Language

There is a significant relationship between the independent variable (ICT) and the two intermediate variables (Cultural Differences among students, English language) according to different levels of the modified variable (Effort expectancy).

Table (4) Regression Weights

\begin{tabular}{lcccccc}
\hline & Parameter & & Estimate & Lower & Upper & P \\
\hline CD & $<--$ & LCG & 0.1341 & -0.0094 & 0.2732 & 0.0694 \\
CD & $<--$ & EEG & -0.0068 & -0.1709 & 0.1606 & 0.9022 \\
CD & $<--$ & LCEEEG & -0.0071 & -0.0399 & 0.0243 & 0.6879 \\
\hline CIE & & & 0.127 & -0.0453 & 0.2697 & 0.1618 \\
CIE_LOW & & 0.1556 & 0.0191 & 0.2771 & 0.0226 \\
CIE_HIGH & & 0.1126 & -0.1194 & 0.2946 & 0.3422 \\
\hline
\end{tabular}

From Table (4), the following is clear:

1. The independent variable (ICT) does not have a significant effect on the mediator variable (Cultural Differences) as well as the modified variables (Effort expectancy) and the interaction between the two variables (adjusted and independent) because the PV value of the regression weights was greater than the level of statistical significance $(0.05)$, which is $(0.07),(0.9),(0.7)$ on the assumption. 


\section{QALAAI ZANISTSCIENTIFIC JOURNAL \\ A Scientific Quarterly Refereed Journal Issued by Lebanese French University - Erbil, Kurdistan, Iraq \\ Vol. (6), No (4), Autumn 2021 \\ ISSN 2518-6566 (Online) - ISSN 2518-6558 (Print)}

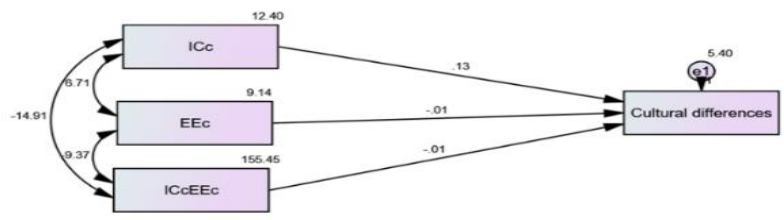

Figure (5): Regression path Coefficients between Var. in the Model

2. The effect of the independent variable (ICT) on the mediating variable (Cultural Differences) was a non-significant effect in the presence of the effect of the modified variable (Effort expectancy) and for you at low levels of the modified variable (Effort expectancy), this effect was significant because the value of (PV) was less. From the level of statistical significance (0.05) and amounting to (0.0226). In other words, if the value of the independent variable changes by one unit, the value of the intermediate variable changes by $(0.16)$, as the value of this effect falls between the confidence limits (0.02-0.28) and the confidence level (0.95) at Low levels of Effort expectancy.

Table (5) Regression Weights

\begin{tabular}{lllrrrr}
\hline Parameter & & & Estimate & S.E. & C.R. & P \\
\hline EL & $<-$ & LCG & 0.0223 & 0.0791 & 0.2816 & 0.7782 \\
\hline EL & $<-$ & EEE & 0.5212 & 0.0895 & 5.8228 & $*$ ** \\
EL & $<-$ & LCEEEG & -0.0232 & 0.0179 & -1.295 & 0.1953 \\
\hline CIE & & & -0.0009 & -0.1599 & 0.1798 & 0.977 \\
\hline CIE_LOW & & & 0.0925 & -0.1093 & 0.2852 & 0.3681 \\
CIE_HIGH & & & -0.048 & -0.2341 & 0.1731 & 0.6411 \\
\hline
\end{tabular}

Through Table No. (5), the following is indicated:

1. The rate variable (Effort expectancy) has a significant effect on the mediator variable (English language) because the value of the (PV) effect of (0.004) was less than the level of statistical significance (0.05). In other words, if the value of the rate variable changes one unit, then the value of the variable the median changes by (0.52), as this value lies between the confidence limits (0.89.5.82) and the level of confidence (0.95). 


\section{QALAAI ZANISTSCIENTIFIC JOURNAL \\ A Scientific Quarterly Refereed Journal Issued by Lebanese French University - Erbil, Kurdistan, Iraq \\ Vol. (6), No (4), Autumn 2021 \\ ISSN 2518-6566 (Online) - ISSN 2518-6558 (Print)}

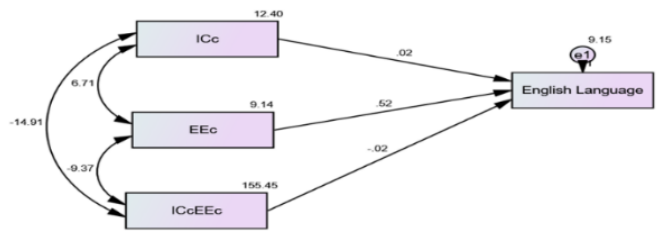

Figure (6): Regression path Coefficients between Var. in the Model

2. The effect of the independent variable (ICT) on the intermediate variable (English language) in the presence of the modified variable (Effort expectancy) and with its different levels (low, high) was insignificant because the values of (PV) were greater than the level of statistical significance $(0.05)$, which is $0.98 ., 0.37,0.64)$ respectively. 3. There is a significant relationship between the independent variable (ICT) and the dependent variables (Management System, (Quality, Performance, Capability, and Value)) in the presence of two mediating variables (Cultural Differences in students, English language) at different levels of the variable. Effort expectancy.

Table (6) Regression Weights

\begin{tabular}{|c|c|c|c|c|c|c|}
\hline Parameter & & & Estimate & Lower & Upper & $\mathbf{P}$ \\
\hline CD & $<$ & 165 & 0.1341 & -0.0191 & 0.2635 & 0.0932 \\
\hline CD & $<-$ & ICEEEE & -0.0071 & -0.0414 & 0.0233 & 0.6327 \\
\hline CD & $<-$ & EEE & -0.0068 & -0.1634 & 0.1676 & 0.9716 \\
\hline MS & $<-$ & $C D$ & 0.5865 & 0.402 & 0.7756 & 0.0004 \\
\hline MS & $<$ & ISE & 0.1692 & 0.0392 & 0.2951 & 0.0093 \\
\hline DE & & & 0.1692 & 0.0392 & 0.2951 & 0.0093 \\
\hline IE & & & 0.0786 & -0.0105 & 0.1664 & 0.0932 \\
\hline CIE_LOW & & & 0.0913 & 0.0108 & 0.1748 & 0.0226 \\
\hline CIE_HIGH & & & 0.066 & -0.0663 & 0.1857 & 0.3422 \\
\hline
\end{tabular}

Through Table No. (6), we note the following:

1. The values of the regression weights for the independent variable (ICT) and the modified variable (Effort expectancy) and the interaction between them on the median variable were insignificant because the (PV) value of the effects values was greater than the level of statistical significance $(0.05)$ which is $(0.09,0.6,0.10)$ In a 


\section{QALAAI ZANISTSCIENTIFIC JOURNAL \\ A Scientific Quarterly Refereed Journal Issued by Lebanese French University - Erbil, Kurdistan, Iraq \\ Vol. (6), No (4), Autumn 2021 \\ ISSN 2518-6566 (Online) - ISSN 2518-6558 (Print)}

row, this means that the above-mentioned variables have no significant effect on the mediator variable (Cultural Differences).

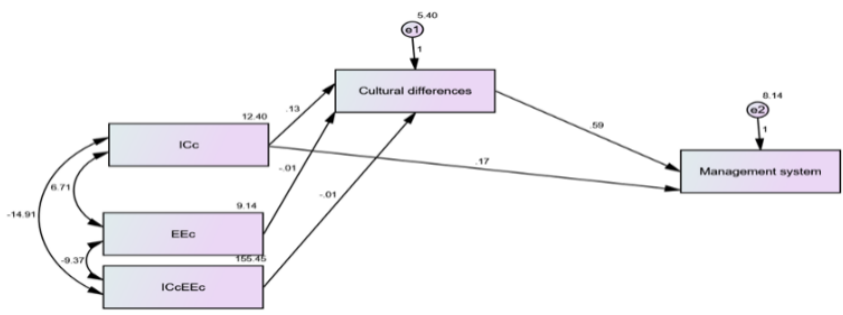

Figure (7): Regression path Coefficients between Var. in the Model

2. The independent variable (ICT) affects the dependent variable (MS) and the mediator variable (CD) has a significant effect on the dependent variable (MS) because the effect (PV) value of (0.004) and (0.0093) was less than the level of statistical significance. (0.05) In other words, if the value of the independent variable or the mediator changes one unit, then the value of the dependent variable changes by (0.59) and (0.17) respectively, as these two values fall between the confidence limits $(0.40,0.78)$ and $(0.04,0.30)$ respectively and at the level of Confidence $(0.95)$.

3. There is a positive significant effect (direct effect) of the independent variable (ICT) on the dependent variable (MS). In other words, if the value of the independent variable changes by one unit, then the values of the dependent variable change by (0.17) because the (PV) value of the said effect was less than the level The statistical significance (0.05) and the amount (0.0093).

4. The indirect effect of the independent variable (ICT) on the dependent variable (MS) through the mediator variable (Cultural Differences) was a non-significant effect in the presence of the modified variable (Effort expectancy), but at low levels of the modified variable (Effort expectancy), this effect was Significantly because the value of (PV) was less than the level of statistical significance (0.05), which is (0.0226). In other words, if the value of the independent variable changes one unit, the value of the dependent variable changes by $(0.09)$, where the value of this effect falls between 


\section{QALAAI ZANISTSCIENTIFIC JOURNAL \\ A Scientific Quarterly Refereed Journal Issued by Lebanese French University - Erbil, Kurdistan, Iraq \\ Vol. (6), No (4), Autumn 2021 \\ ISSN 2518-6566 (Online) - ISSN 2518-6558 (Print)}

the confidence limits $(0.17,0.01)$ And a confidence level $(0.95)$ at the low levels of the modified variable (Effort expectancy).

\begin{tabular}{|c|c|c|c|c|c|c|c|}
\hline \multicolumn{8}{|c|}{ Table (7) Regression Weights } \\
\hline Parameter & & & Estimate & Lower & Upper & $\mathbf{P}$ & \\
\hline EL & $<-$ & 165 & 0.0223 & -0.1363 & 0.1921 & & 0.8037 \\
\hline EL & $<-$ & ISCEEEC & -0.0232 & -0.06 & 0.0151 & & 0.2556 \\
\hline EL & $<-$ & EEEC & 0.5212 & 0.3235 & 0.7426 & & 0.0004 \\
\hline MS & $<-$ & EL & 0.2566 & 0.1027 & 0.4186 & & 0.0006 \\
\hline MS & $<-$ & 165 & 0.1654 & 0.0022 & 0.3288 & & 0.045 \\
\hline DE & & & 0.1654 & 0.0022 & 0.3288 & & 0.045 \\
\hline IE & & & 0.0057 & -0.0358 & 0.0607 & & 0.8033 \\
\hline CIE_LOW & & & 0.0237 & -0.0273 & 0.0891 & & 0.3677 \\
\hline CIE_HIGH & & & -0.0123 & -0.0667 & 0.0527 & & 0.6415 \\
\hline
\end{tabular}

Through Table No. (7), we note the following:

The two independent variables (ICT) and the interaction between the (independent and modified) variable on the intermediate variable (English language) do not have a significant effect, because the PV value of the effects of the two mentioned variables $(0.8,0.26)$ was greater than the level of statistical significance $(0.05)$. This indicates on the insignificance of the two effects. We also note that the effect of the rate variable (EE) on the mean variable (EL) of (0.52) was significant because the value of (PV) is less than the level of statistical significance (0.05). In other words, if the values of the rate variable change by one unit, the value of the mediator variable changes by $(0.52)$ and it lies between the confidence limits $(0.32-0.74)$ and the confidence level $(0,95)$.

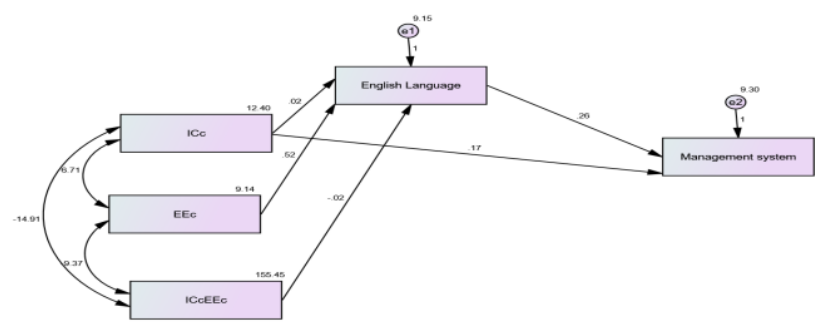

Figure (8): Regression path Coefficients between Var. in the Model 


\section{QALAAI ZANISTSCIENTIFIC JOURNAL \\ A Scientific Quarterly Refereed Journal Issued by Lebanese French University - Erbil, Kurdistan, Iraq \\ Vol. (6), No (4), Autumn 2021 \\ ISSN 2518-6566 (Online) - ISSN 2518-6558 (Print)}

2. The independent variable (ICT) and the median (EL) affect the dependent variable (MS) as the regression weights of the two influencing variables, amounting to $(0.16,0.26)$ respectively, were statistically significant (because the value of $(P V)$ is less than the level of statistical significance (0.05). This means that if the values of the two influencing variables change by one unit, then the values of the adopted variable change by the amount of the mentioned values with confidence limits $(0.02,0.33)$, (0.19-0.42) respectively, and the level of confidence $(0,95)$.

3. There is no significant (indirect) effect of the independent variable () on the dependent variable () in the presence of the mediator variable and with different values of the rate variable and the various levels () because the value of (P.V) is greater than the level of statistical significance (0.05).4. Effort expectancy are positively related to ICT (H2a), Management System, (Quality, Performance, Capability, Value) $(\mathrm{H} 2 \mathrm{~b})$. And also, positively relate to Mediates of Cultural Differences, English Language $(\mathrm{H} 2 \mathrm{c})$.

The second hypothesis is divided into: 1 . there is a positive significant relationship between the modified variable (Effort expectancy) and the independent variable (ICT). 2. There is a positive significant relationship between the modified variable (Effort expectancy) and the dependent variables (Quality, Performance, Capability, Value). 3. There is a positive significant relationship between the modified variable (Effort expectancy) and the two mediating variables (Cultural Differences, English Language).

Through the table of correlation matrix, we note the following:

1. There was a positive (direct) significant relationship between the variables (EE-EL, EE-MS, EE-ICT) because the value of the correlation coefficients was greater than the level of significance and the values of the correlation coefficient were $(0.63,0.25,0.49)$, respectively. 2 . There is no significant correlation between the variables (EE-CD) because the value of the correlation coefficient was greater than the level of significance, which is (0.069) Cultural Differences, English Language 


\section{QALAAI ZANISTSCIENTIFIC JOURNAL}

A Scientific Quarterly Refereed Journal Issued by Lebanese French University - Erbil, Kurdistan, Iraq

Vol. (6), No (4), Autumn 2021

ISSN 2518-6566 (Online) - ISSN 2518-6558 (Print)

backgrounds affect student's Effort expectancy (H3a), ICT (H3b), utilization in Management System, (Quality, Performance, Capability, and Value) (H3c).

The third hypothesis is divided into:

1. The existence of a significant effect of the two mediated variables (Cultural Differences, English Language) on the modified variable (Effort expectancy). 2. There is a significant effect of the two mediated variables (Cultural Differences, English Language) on the independent variable (ICT). 3. There is a significant effect of the two mediated variables (Cultural Differences, English Language) on the attributed variables represented by the use of management systems (Quality, Performance, Capability, and Value).

\begin{tabular}{|c|c|c|c|c|}
\hline \multicolumn{5}{|c|}{ Table (8) Regression Weights } \\
\hline & Parameter & & Estimate & $\mathbf{P}$ \\
\hline EE & $<-$ & $\mathrm{CD}$ & -0.0368 & 0.6493 \\
\hline EE & $<-$ & EL & 0.4311 & $* * *$ \\
\hline IC & $<-$ & $\mathrm{CD}$ & 0.1657 & 0.1015 \\
\hline IC & $<-$ & EL & 0.3048 & $* * *$ \\
\hline MS & $<-$ & CD & 0.5486 & $* * *$ \\
\hline MS & $<-$ & EL & 0.1961 & $* * *$ \\
\hline
\end{tabular}

Through Table (8) and (9), we note the following:

1. The mediated variable $(C D)$ does not have significant effect on the rate variable (EE) because the value of (PV) is greater than the level of statistical significance (0.05) which is (0.65).

Table (9) Regression Weights

\begin{tabular}{lr}
\hline Parameter & $\begin{array}{r}\text { Estimat } \\
\text { e }\end{array}$ \\
MS & 0.2523 \\
IC & 0.1244 \\
EE & 0.2384 \\
\hline
\end{tabular}

Also, it's noted that there is a significant effect because the value of (PV) is less than the level of statistical significance. (0.05) and the amount of $(0.000)$ for the mediated 


\section{QALAAI ZANISTSCIENTIFIC JOURNAL \\ A Scientific Quarterly Refereed Journal Issued by Lebanese French University - Erbil, Kurdistan, Iraq \\ Vol. (6), No (4), Autumn 2021 \\ ISSN 2518-6566 (Online) - ISSN 2518-6558 (Print)}

variable (EL) over the rate variable (EE). In other words, if the values of the mediated variable change by one unit, the values of the rate variable change by $(0.43)$, as in Table No. (8).

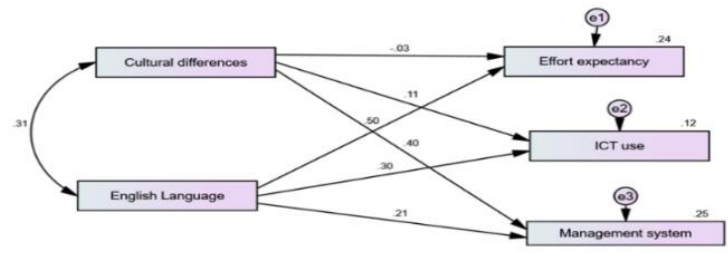

Figure (9): Regression path Coefficients between Var. in the Model

2. The non-significant effect of the mediating variable (CD) on the independent variable (ICT) because the (PV) value of the regression weight is greater than the level of statistical significance $(0.05)$ of $(0.10)$, also it's noted that there is a significant effect of the mediating variable (EL) on the independent variable. (ICT) Because the value of (PV) of the regression weight is less than the level of statistical significance (0.05), which is (0.000). In other words, if the values of the mean variable change by one unit, the values of the rate variable change by (0.30), as in Table No. (8).

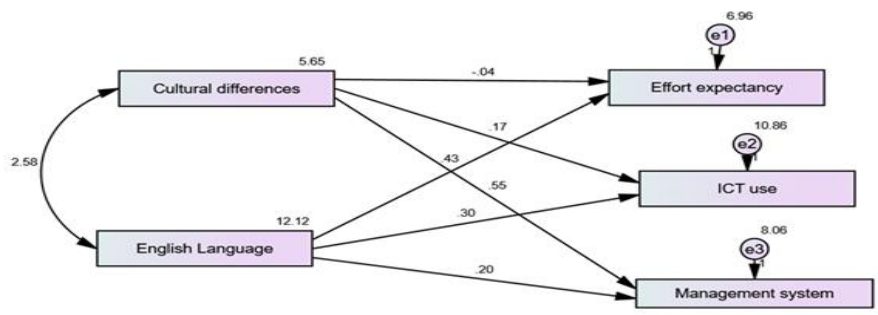

Figure (10): Regression path Coefficients between Var. in the Model

3. The significant effect of the two mediating variables (Cultural Differences, English Language) on the dependent variable (ICT) because the value of (PV) is less than the level of statistical significance (0.05) and is $(0.000)$ for both effects. In other words, if the values of the two mediating variables change one unit, then the values of the 


\section{QALAAI ZANISTSCIENTIFIC JOURNAL \\ A Scientific Quarterly Refereed Journal Issued by Lebanese French University - Erbil, Kurdistan, Iraq \\ Vol. (6), No (4), Autumn 2021 \\ ISSN 2518-6566 (Online) - ISSN 2518-6558 (Print)}

dependent variable change by $(0.20), 0.55)$ respectively and as in Table No. (8). 4 . The frequent interpreted percentage $(25 \%, 12 \%, 24 \%)$ of the frequent occurring changes in the variables (EE, ICT, MS) were caused by the two mediating variables (CD, EL), as shown in Table (9). 5. Management System, (Quality, Performance, Capability, and Value), are positively relate to ICT, ( $\mathrm{H} 4 \mathrm{a})$, Moderating of Effort expectancy ( $\mathrm{H} 4 \mathrm{~b})$, and Mediates of Cultural Differences \& English Language ( $\mathrm{H} 4 \mathrm{c})$.

Assumption No. 4 branches out into:

1. There is a positive significant correlation between the dependent variables (Quality, Performance, Capability, and Value) and the independent variable (ICT). 2. There is a significant effect of the independent variable (ICT) on the dependent variables (Quality, Performance, Capability, and Value) in the incidence of the modified variable (Effort expectancy). 3. Does the effect of independent variable (ICT) change on the dependent variables (Quality, Performance, Capability, and Value) according the modified variable (Effort expectancy) with the incidence of the two intermediating variables (Cultural Differences \& English Language)?

1. through the correlation matrix table No. (), we find a positive direct relationship, where the value of the correlation coefficient was 0.3 , and it was significant as the value of () for the value of the coefficient is less than the level of statistical significance (0.05). 2. The nonappearance of significant effects of the variables (ICT), (EE) and the interaction between them on the dependent variable (MS) since the ( $p$ value) of the regression weights was greater than the level of statistical significance (0.05).

\begin{tabular}{|c|c|c|c|c|}
\hline \multicolumn{5}{|c|}{ Table (10) Regression Weights } \\
\hline Parameter & Estimate & Lower & Upper & $\mathbf{p}$ \\
\hline DE & 0.1504 & -0.1409 & 0.3961 & 0.3924 \\
\hline CDE & 0.1322 & -0.2099 & 0.4099 & 0.5294 \\
\hline CDE_LOW & 0.2056 & -0.0279 & 0.4163 & 0.0897 \\
\hline CDE_HIGH & 0.0952 & -0.3707 & 0.4566 & 0.7554 \\
\hline
\end{tabular}

Through Table (10), the following are noted: There is no significant effect (direct and indirect) of the independent variable (ICT) on the dependent variable (MS) with in the 


\section{QALAAI ZANISTSCIENTIFIC JOURNAL \\ A Scientific Quarterly Refereed Journal Issued by Lebanese French University - Erbil, Kurdistan, Iraq \\ Vol. (6), No (4), Autumn 2021 \\ ISSN 2518-6566 (Online) - ISSN 2518-6558 (Print)}

occurrence of the rate variable (EE) and with its different levels (low, high) because the (pv) value of the regression effects' weight was greater than the level of statistical significance (0.0.5).

\begin{tabular}{lrrrr}
\hline \multicolumn{7}{c}{ Table (12) Regression Weights } & & \\
\hline \multicolumn{1}{c}{ Parameter } & Estimate & Lower & Upper & P \\
\hline DE & 0.1519 & -0.0526 & 0.3398 & 0.1667 \\
CDE & 0.1393 & -0.117 & 0.364 & 0.336 \\
\hline CDE_LOW & 0.1898 & 0.0225 & 0.3603 & 0.0242 \\
CDE_MED & 0.1519 & -0.0526 & 0.3398 & 0.1667 \\
\hline CDE_HIGH & 0.114 & -0.2626 & 0.4288 & 0.6027 \\
IE & 0.0056 & -0.0354 & 0.0602 & 0.8037 \\
\hline CIE_LOW & 0.0233 & -0.0274 & 0.0864 & 0.3681 \\
CIE_HIGH & -0.0121 & -0.0642 & 0.0527 & 0.6419 \\
\hline CIE_MED & 0.0056 & -0.0354 & 0.0602 & 0.8037 \\
\hline
\end{tabular}

Through Table (11), we find that there is no significant effect of the independent variable (ICT) on the dependent variable (MS) in the presence of the rate variable (EE) at different levels (med, High) since the (PV) value of the regression weight was greater than the level of statistical significance $(0.05)$, But at low levels of interaction, that is, because of the rate variable (EE), the direct effect of the independent variable on the dependent variable becomes significant as the value (PV) of the regression weight of the low effect was (0.0242) significant, and the value of (PV) is less than The level of statistical significance is (0.05).

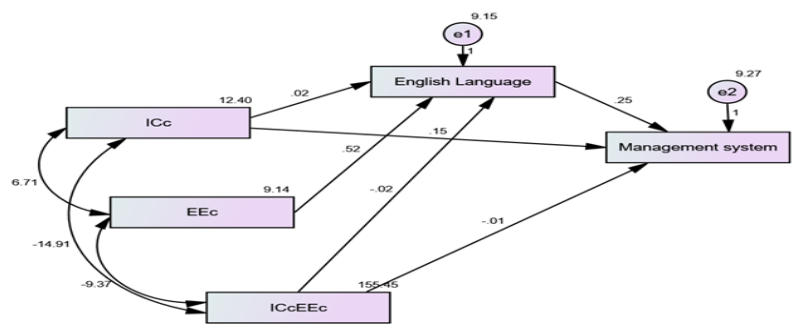

Figure (11): Regression path Coefficients between Var. in the Model

Also, through the same table, regardless of the significance value or the insignificance of the effects, it's noted that the value of the direct effect of the independent variable on the dependent variable decreases as the levels of the rate variable increase for the 


\section{QALAAI ZANISTSCIENTIFIC JOURNAL \\ A Scientific Quarterly Refereed Journal Issued by Lebanese French University - Erbil, Kurdistan, Iraq \\ Vol. (6), No (4), Autumn 2021 \\ ISSN 2518-6566 (Online) - ISSN 2518-6558 (Print)}

regression weight decreases from $(0.18)$ to $(0.15)$ and then to $(0.11)$, this indicates that the smaller the levels of the modified variable, the greater the direct effect between the independent and dependent variables.

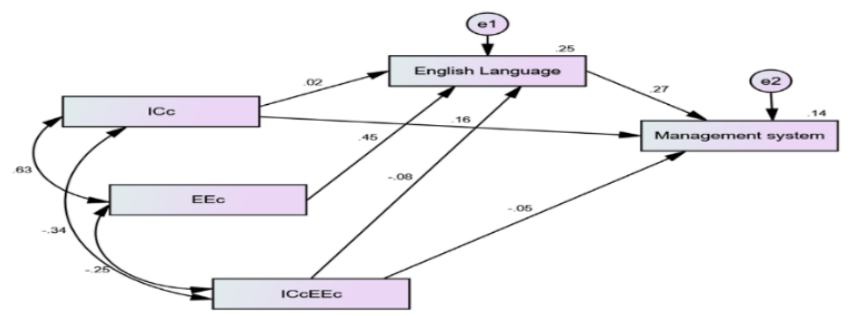

Figure (12): Regression path Coefficients between Var. in the Model

Through Table (12), it's clear that there is no significant indirect effect of the independent variable (ICT) on the dependent variable (MS) through the mediating variable () in accordance of the rate variable (EE) with its different levels (med, High) because the value of (PV) of the regression weight was greater than the level of statistical significance (0.05), but at low levels of interaction, that is, in according the rate variable $(E E)$, the direct effect of the independent variable on the dependent variable becomes significant because the value (PV) of the regression weight of the low effect was (0.013) Significantly, since the value of (PV) is less than the level of statistical significance (0.05).

\begin{tabular}{|c|c|c|c|c|}
\hline Barameter & Evatmate & Lawer & Upper & D \\
\hline DE & 0.151 & -0.0016 & 0.2892 & 0.0525 \\
\hline CDE & 0.1355 & -0.0549 & 0.2962 & 0.1584 \\
\hline CDE_LOWW & 0.1979 & 0.0442 & 0.3585 & 0.0131 \\
\hline CDE_MED & 0.151 & -0.0016 & 0.2892 & 0.0525 \\
\hline CDE_HICH & 0.1041 & -0.1752 & 0.3276 & 0.472 \\
\hline Ie & 0.0789 & -0.0103 & 0.1657 & 0.0932 \\
\hline CIE_LOW & 0.0908 & 0.0108 & 0.1723 & 0.0225 \\
\hline CIE_HOH & 0.0657 & -0.062 & 0.1839 & 0.3422 \\
\hline CIE_MED & 0.0789 & -0.0103 & 0.1657 & 0.0932 \\
\hline
\end{tabular}




\section{QALAAI ZANISTSCIENTIFIC JOURNAL \\ A Scientific Quarterly Refereed Journal Issued by Lebanese French University - Erbil, Kurdistan, Iraq \\ Vol. (6), No (4), Autumn 2021 \\ ISSN 2518-6566 (Online) - ISSN 2518-6558 (Print)}

Also, through the same table, regardless of the significant or insignificant value of the effects, it's noted that the value's direct effect of the independent variable gradually decreases on the dependent variable as the levels of the rate variable increase.

\subsection{Rcommendations}

The following recommendations are made on the basis of major findings:

1-One of the major findings of the study reveals that there is a direct relationship ICT and student's management skills through English language learning. Therefor it's recommended ICT should be integrated generously to English language courses to ensure students better learning quality. 2-Students expected to put more effort into learning English language using up to date technological programs and apps, as there is a great correlation between English language and effort expectancy. 3-No significant difference has been found between cultural differences and effort expectancy. On the basis of this findings cultural background shouldn't be used as a justification for the amount of effort student's use in achieving their ICT and language qualifications. 4-another finding of the study reveals that there is a direct among online course, English language, and management system; students' performance, quality, capability and value, therefore students are recommended to spend more time exploiting the potential of online courses and platforms to make the journey of English language efficaciously. 5-Information and Communication Technologies should be vital part of the university curricula. 6- Constant workshops and training courses should be conducted to train and update the teaching staff of modern ICT resources. 7- Main ICT labs must be stablished at all colleges supplying students need with computers, network, IT specialists and other necessary technological equipment when it arises. 8- Further research studies need to be conducted on this topic with different methods of data collection using qualitative approach to generate more demanding findings.

\subsection{Discussion and Conclusion}

The essential need for English language as a mean of communication and the technological evolution in the past few decades have lifted up teaching/learning 


\section{QALAAI ZANISTSCIENTIFIC JOURNAL \\ A Scientific Quarterly Refereed Journal Issued by Lebanese French University - Erbil, Kurdistan, Iraq \\ Vol. (6), No (4), Autumn 2021 \\ ISSN 2518-6566 (Online) - ISSN 2518-6558 (Print)}

process to unexpected extent. The present study offers a detailed analysis of 209 questionnaire forms submitted by freshman students who have covered both semesters of year 2020-2021 throughout unexceptional experience. The scope of the research is limited to the use if ICT in learning English language and students' management skill in generating fruitful learning outcomes though in class and electronic/online learning during the Pandemic COVID19 period. It illustrates that in the first course the use of ICTs in education has a positive impact on the academic achievement of the students. The several research data analyses also brought up the fact that there is a direct relationship between ICT use, English language, cultural differences, and learning management system; students' performance, quality, capability and value. Correspondingly effort expectancy significantly contributes to English language and management system, but concerning the relation exist between effort expectancy and cultural differences the very opposite is true.

On the other hand, while students were imposed to endure their study of the second course virtually during the first and second waves of the coronavirus pandemic. The data analysis reveals that there is an identical significant relationship among online course, English language, and management system; students' performance, quality, capability and value. Similarly, effort expectancy has a significant impact on English language and management system.

Taking into consideration all of the above facts, the ICT can serve students learning to a great extent, specifically via online/ distance learning. Therefore, student's limited skills and management experience certainly need to be improved for a better-quality language education. Also, to cope with the most current developments of Higher education in the world.

\section{REFERENCES:}

1. ^ Berry, Kim and Boski (1988), there must be an awareness of the various "psychological acculturation" processes of ... Psychological acculturation of immigrants ResearchGatehttps://www.researchgate.net > publication > 311102389_... 


\section{QALAAI ZANISTSCIENTIFIC JOURNAL \\ A Scientific Quarterly Refereed Journal Issued by Lebanese French University - Erbil, Kurdistan, Iraq \\ Vol. (6), No (4), Autumn 2021 \\ ISSN 2518-6566 (Online) - ISSN 2518-6558 (Print)}

2. ^ Black, Mendenhall \& Oddou (1991) Job factors, such as role conflict inhibits adjustment while role clarity reduces uncertainty and. Toward a Comprehensive Model of International https://www.researchgate.net > publication > 23402135...

3. ^ Gnutzmann \& Intemann, (2008). English as a Lingua Franca in Higher Education: A ... Page 45books.google.iq > books.

4. ^ Hofstede and Bond (1984), more emphasis on if job-related achievements are recognized by others in collectivist society while ... Hofstede's Culture Dimensions an Independent https://www.researchgate.net > publication > 24772363...

5. ^ Mick Will (2019), An Operations Guide to Safety and Environmental Management ...books.google.iq > books.

6. ^ Nick Milton, Patrick Lambe (2019), The Knowledge Manager's Handbook: A Step-byStep Guide to ...books.google.iq > books A Step-by-Step Guide to Embedding Effective Knowledge Management in your ... 2015b).

7. ^ Popular Mechanics, (2000). Page 2books.google.iq , books , id=LOsPSCAN29gC. Magazine.

8. A Shivangi Dhawan1 (2020), Online Learning: A Panacea in the Time of COVID-19 Crisis, Journal of Educational Technology Systems. 2020 Sep; 49(1): 5-22. doi: 10.1177/0047239520934018.

9. ^ Tuan Nguyen (2015), The Effectiveness of Online Learning: Beyond No Significant Difference and Future Horizons....https://www.researchgate.net , publication , 308171318_...

10. ^Mathur, Piyush (2017) Technological Forms and Ecological Communication: A Theoretical Heuristic (Lanham, Boulder, New York, London), pp. 200-202.

11. ^ Motshegwe, Molefe Mookana and Batane, Tshepo (2015) "Factors Influencing Instructors' Attitudes toward Technology Integration, "Journal of Educational Technology Development and Exchange (JETDE): Vol. 8: Iss. 1, Article 1.DOI: 10.18785/jetde.0801.01

12. James (2011-12-18). "Cloud network architecture and ICT - Modern Network Architecture". TechTarget =IT Knowledge Exchange. Archived from the original on 201709-20. Retrieved 2013-08-18. 


\section{QALAAI ZANISTSCIENTIFIC JOURNAL}

A Scientific Quarterly Refereed Journal Issued by Lebanese French University - Erbil, Kurdistan, Iraq

Vol. (6), No (4), Autumn 2021

ISSN 2518-6566 (Online) - ISSN 2518-6558 (Print)

كاريكُرى فيربوونى زانياره تهكنهلوَجيا، خويَندن به ئوَنلاين، وسيستهمى

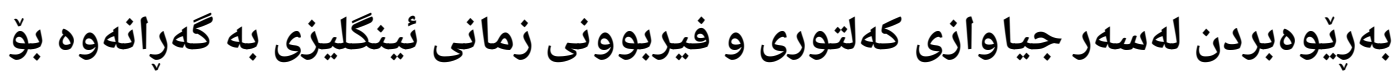

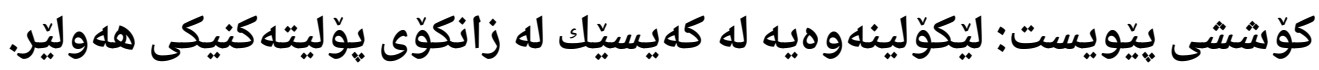

ئامانج و زمهينه:

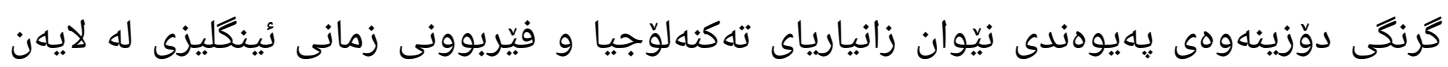

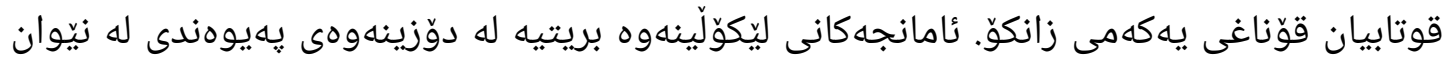

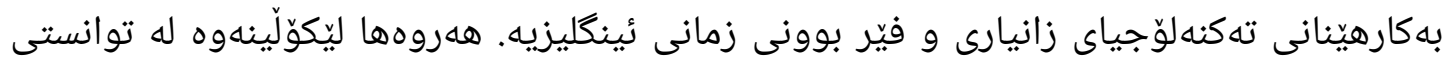

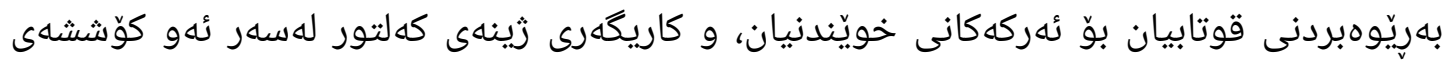

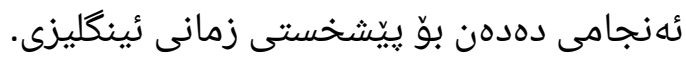

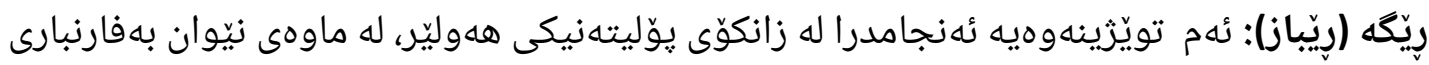

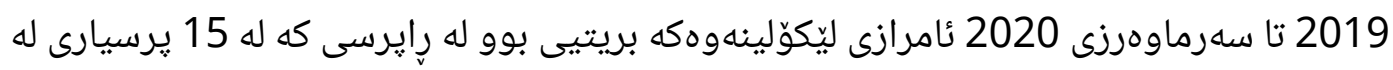

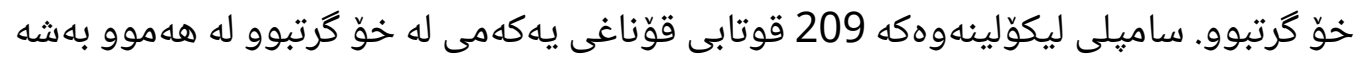

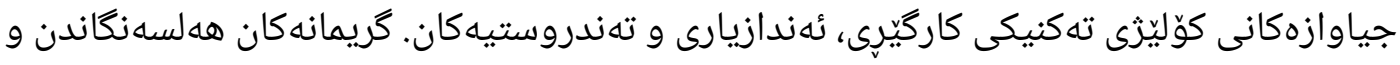

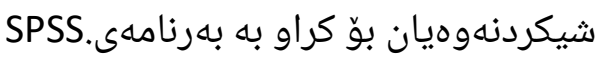

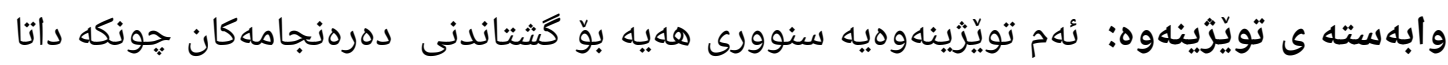

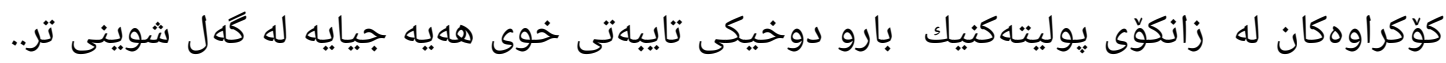

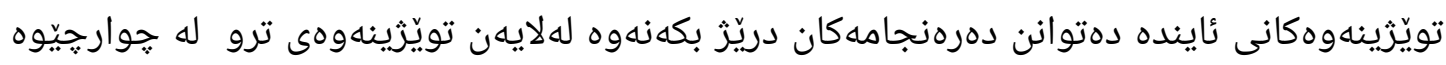
زانكوّى ديكه ئهنجامى بدهن. 


\section{QALAAI ZANISTSCIENTIFIC JOURNAL}

A Scientific Quarterly Refereed Journal Issued by Lebanese French University - Erbil, Kurdistan, Iraq

Vol. (6), No (4), Autumn 2021

ISSN 2518-6566 (Online) - ISSN 2518-6558 (Print)

تأثثر اكتساب تكنولوجيا المعلومات والاتصالات ، الدراسة عبر الإنترنت ، ونظام الإدارة على الإنى

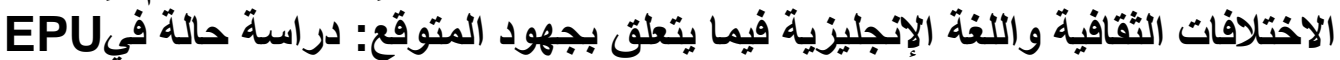

الهذف والخلفية:

الهية اكتثاف العلاقة بين استخدام تكنولوجيا المعلومات والاتصالات وإنجاز الطلاب في اللغة الإنجليزية في

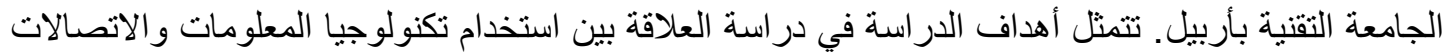

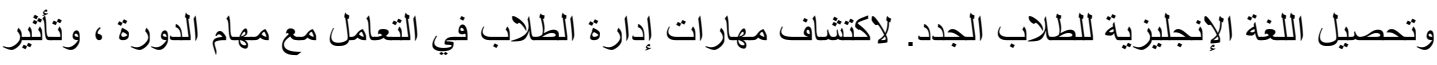

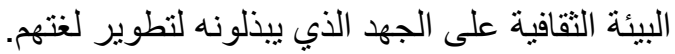

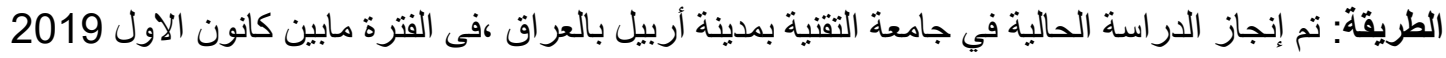

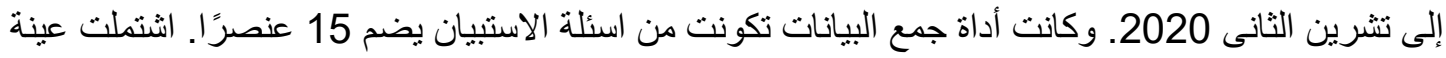

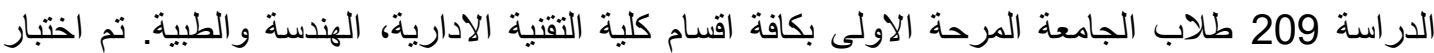

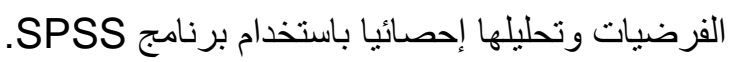

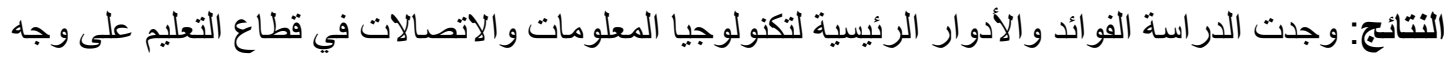

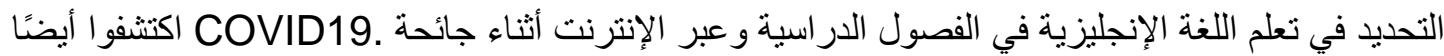

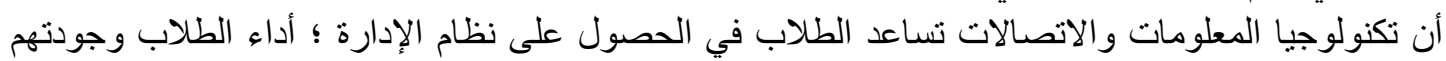

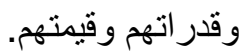

